\title{
Modification of Spray-Method for Producing of Single-Walled Carbon Nanotubes Films and Their Properties
}

\author{
Anton S. Voronin ${ }^{\mathrm{a}, \mathrm{b}, \mathrm{c} *}$, \\ Fedor S. Ivanchenko ${ }^{a, b}$, Michael M. Simunin ${ }^{b, d}$, \\ Aleksei I. Lyamkin ${ }^{a, c}$, Yuri V. Fadeev ${ }^{\text {, }}$ \\ Aleksey V. Shiverskiy ${ }^{\mathrm{a}, \mathrm{b}}$ and Stanislav V. Khartov ${ }^{\mathrm{b}, \mathrm{c}}$ \\ ${ }^{a}$ Siberian Federal University \\ 79 Svobodny, Krasnoyarsk, 660041, Russia \\ ${ }^{b}$ Ltd. «FunNano» \\ 50 Akademgorodok, Krasnoyarsk, 660036, Russia \\ ${ }^{c}$ Molecular Electronic Department, KSC SB RAS \\ 50 Akademgorodok, Krasnoyarsk, 660036, Russia \\ ${ }^{d}$ National Research University «MIET» \\ 5 travel 4806, Zelenograd, Moscow, 124498, Russia
}

The technique of forming thin films of single-walled carbon nanotubes by ultrasonic spraying an aqueous dispersion. The developed technique allows to form a film of single-walled carbon nanotubes of large area and highly homogeneous. The technique allows to form a nanotube coating on the surfaces of complex shape. Using this method, the transparent electrodes are formed characterized by transparency of $77 \%$ and a surface resistivity of $210 \mathrm{ohms} / \mathrm{square}$, and transparency in the infrared range of more than $91 \%$.

Keywords: single-walled carbon nanotube transparent electrodes, ultrasonic spraying, optoelectronics.

(c) Siberian Federal University. All rights reserved

* Corresponding author E-mail address: a.voronin1988@mail.ru 


\title{
Модифицирование spray- метода
}

\section{для получения пленок \\ однослойных углеродных нанотрубок}

\section{и их свойства}

\author{
А.С. Воронин ${ }^{\mathrm{a}, \tilde{\sigma, s}}$, Ф.С. Иванченко ${ }^{\mathrm{a}, \tilde{\sigma}}$, \\ М.М. Симунин ${ }^{\sigma, г}$, А.И. Лямкин ${ }^{\mathrm{a}, \mathrm{s}}$, \\ Ю.В. Фадеев ${ }^{\sigma}$, А.В. Шиверский ${ }^{\mathrm{a}, \tilde{0}}$, С.В. Хартов ${ }^{\tilde{\sigma}, \mathrm{s}}$ \\ ${ }^{\text {a } С и б и р с к и и ̆ ~ ф е д е р а л ь н ы и ̆ ~ у н и в е р с и т е т ~}$ \\ Россия, 660041, Красноярск, пр. Свободный, 79 \\ ${ }^{6} \mathrm{OOO} \mathrm{«ФанНано»}$
}

Россия, 660036, Красноярск, Академгородок, 50

${ }^{8}$ Отдел молекулярной электроники КНЦ СО РАН

Россия, 660036, Красноярск, Академгородок, 50

${ }^{2}$ Национальный исследовательский университет «МИЭТ» Россия, 124498, Москва, Зеленоград, проезд 4806, 5

\begin{abstract}
Разработана методика формирования тонких пленок однослойных углеродных нанотрубок посредством ультразвукового распыления водной дисперсии. Методика позволяет формировать пленки однослойных углеродных нанотрубок большой площади и высокой однородности, на поверхностях сложной формы. При помощии данной методики сформированы прозрачные электроды, характеризующиеся прозрачностью 77 \% и удельным поверхностным сопротивлением 210 Ом/кв, а также прозрачностью в инфракрасном диапазоне более $91 \%$.
\end{abstract}

Ключевые слова: однослойные углеродные нанотрубки, прозрачные электроды, ультразвуковое распыление, оптоэлектроника.

\section{Введение}

Прозрачные электроды имеют существенное практическое значение [1]. Они находят своё применение для изготовления таких объектов техники, как электрохромные стёкла [2]; электроды для органических светодиодов [3], электронной бумаги, солнечных батарей [4], различных оптоэлектронных приборов; а также защита от электростатики, система экранирования электромагнитных полей и др.

На текущий момент наиболее распространённым техническим решением является применение покрытий, выполненных на основе проводящих оксидов металлов [5]. В частности, широко используется покрытие на основе индий-оловянного оксида (ITO). К основным недостаткам покрытий данного типа следует отнести довольно высокую стоимость и прогноз её повышения, существенные ограничения по допустимым подложкам (обусловлено методом формирования), значительную потерю прозрачности в ИК-области спектра, низкую механическую гибкость и эластичность. Преимущество - высокое соотношение оптической прозрачности и поверхностного сопротивления: 10 Ом/кв при 80 \% прозрачности. 
Однослойные углеродные нанотрубки (ОУНТ) интенсивно исследуются для их дальнейшего применения в электронике [6]. Одной из возможных областей, где ОУНТ могут раскрыть свой потенциал, признано изготовление оптически прозрачных проводящих пленок [7-9]. В отличие от оксидных прозрачных электродов нанотрубные обладают высокой гибкостью и прозрачностью в ИК-диапазоне. Наиболее перспективными методиками формирования пленок ОУНТ большой площади являются spray-метод [10-12] и метод микроструйной печати (ink jet) [13].

\section{Методика формирования тонких пленок ОУНТ}

Главным недостатком классического spray-метода выступает большой размер капель - 30 50 мкм, в результате чего происходит их слияние, что создает оптические неоднородности на пленке.

Предлагаемая методика формирования пленок ОУНТ позволяет решить проблему макроскопических неоднородностей за счет применения ультразвукового диспергирования коллоидной системы вода+ОУНТ (использовали ультразвуковой ингалятор модели «РОТОР» Муссон$1 \mathrm{M}$, рабочая частота 2,64 МГц). При этом происходит формирование и отрыв микрокапель с поверхности коллоидного раствора. Размер капель имеет различное наполнение, которое очень зависит от степени агрегации коллоида, и находится в диапазоне 3-5 мкм. Получившийся аэрозоль ОУНТ подается в рабочую камеру, где разбивается потоком воздуха о подложку. На рис. $1 a$ показана схема процесса синтеза тонких пленок ОУНТ.

Главными параметрами контроля получаемых пленок служат концентрация коллоида и время напуска аэрозоля. На рис. 16 представлены расчетные зависимости толщин пленок ОУНТ от количества импульсов осаждения для стабильного коллоидного раствора с концентрацией нанотрубок 4·10-3 г/л при различных временах напуска (1, 2 и 3 c). Увеличение времени напуска аэрозоля ведет к коалесценции капель, в результате которой на подложке появляются неоднородности.

При наличии в коллоидном растворе агрегатов нанотрубок, а также элементов с линейным размером более 5 мкм за счет кавитации происходит разрушение стуктуры материала в агрегатах и микрокапли наполняются фрагментами нанотрубок.
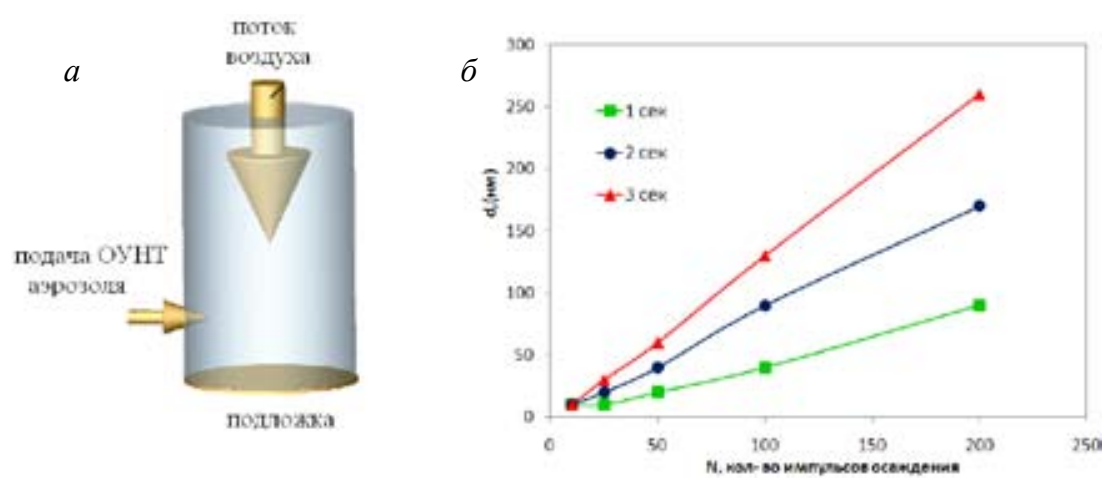

Рис. 1: $a$ - схема формирования пленок ОУНТ модифицированным spray-методом; $\sigma$ - зависимость толщины пленок ОУНТ от количества импульсов осаждения для трех времен напуска аэрозоля 


\section{Синтез образцов и методика эксперимента}

В качестве материала для синтеза пленок ОУНТ были использованы ОУНТ, полученные методом электродогового испарения на катализаторе Ni/Y. Нанотрубный материал получен А.В. Крестининым (ИПХФ РАН, ООО «Углерод ЧГ»), содержание ОУНТ 90 \%, средний диаметр нанотрубок 1,5 нм. Степень агрегации низкая, материал представляет собой тяжи нанотрубок длиной 2-10 мкм и радиусом до 10 нм.

Концентрация ОУНТ в водной дисперсии составляла $4 \cdot 10^{-3}$ г/л. Для стабилизации дисперсии в раствор вводили цетилтриметиламмоний бромид (ЦТАБ) с содержанием $4 \cdot 10^{-4} \Gamma /$. Дальнейшее повышение концентрации ЦТАБ замедляет процесс высыхания капель, и на пленке появляются разводы.

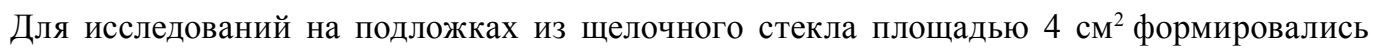
пленки ОУНТ четырех видов толщины $(50,100,150$ и 200 итераций). Время единичного напуска аэрозоля составляло 2 с. После каждой итерации система сушилась в течение 30 с. Для удаления ЦТАБ готовые пленки ОУНТ отжигали на воздухе при $400{ }^{\circ} \mathrm{C}$ в течение 60 с. Макрои микроструктура пленки ОУНТ толщиной 100 итераций показана на рис. 2.

Изображения демонстрируют высокую однородность пленки ОУНТ как на макро-, так и на микромасштабе, что является доказательством перспективности разработанного метода.

После процедуры отжига пленки ОУНТ подвергались дырочному допированию обработкой пленок в парах азотной кислоты. Обработка проводилась по методике, описанной в [14], время экспонирования составляло 2,5 ч. При воздействии на ОУНТ парами азотной кислоты происходит функционализация боковой поверхности карбоксильными, карбонильными и гидроксильными группами [15].

Макроструктура пленок изучалась при помощи оптического микроскопа. Для исследования микроструктуры пленок ОУНТ использовался сканирующий электронный микроскоп Hitachi S 5500.
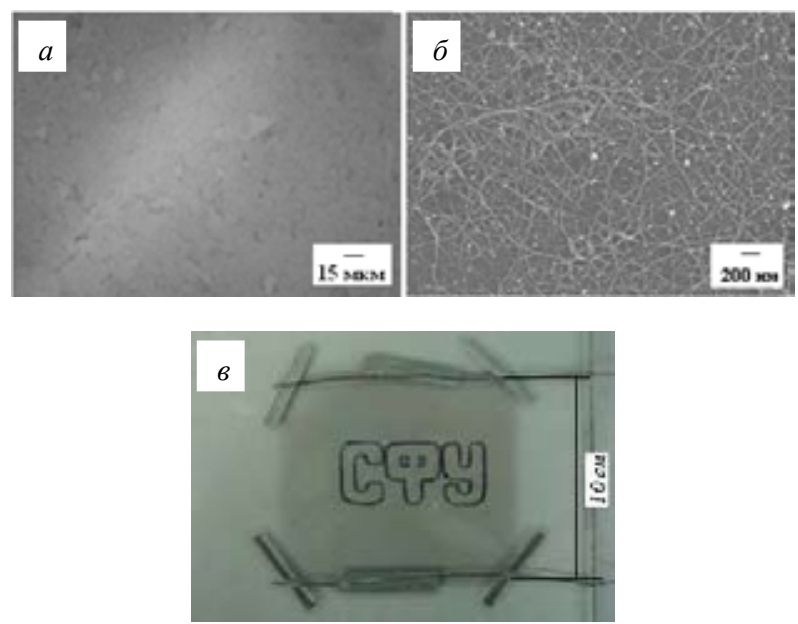

Pис. 2: $a$ - макроструктура пленок ОУНТ (100 итераций осаждения); $\sigma$ - микроструктура пленок ОУНТ (100 итераций осаждения); 8 - демонстрация высокой однородности и прозрачности пленки ОУНТ (100 итераций осаждения) 
Для измерения поверхностного сопротивления на пленках ОУНТ магнетронным напылением формировалась пара медных контактов толщиной 150 нм.

Измерения оптического пропускания пленок в диапазоне 400-2000 нм производились при помощи спектрофотометра Shimadzu UV 3600.

\section{Результаты и обсуждение}

Пронализируем спектры оптического пропускания пленок ОУНТ (рис. 3a) на подложках из щелочного стекла различной толщины (50, 100, 150, 200 итераций осаждения). Пики поглощения соответствуют электронным переходам между особенностями ван Хова в плотности состояний одномерных систем $[16,17]$, для полупроводниковых $\left(\lambda\left(\mathrm{S}_{11}\right)=1873\right.$ нм и $\lambda\left(\mathrm{S}_{22}\right)=1036$ нм) и металлических $\left(\lambda\left(\mathrm{M}_{11}\right)=712\right.$ нм) нанотрубок. Из спектров видно, что пики переходов для металлических трубок проявляются слабее пиков, соответствующих полупроводниковым переходам, из чего можно сделать вывод о меньшем процентном содержании металлических УНТ в исходной пасте нанотрубок. В действительности литературные данные показывают, что при дуговом методе синтеза ОУНТ на выходе получается 1/3 металлических и 2/3 полупроводниковых нанотрубок различной хиральности [18]. После операции экспонирования пленок парами азотной кислоты спектральные зависимости оптического пропускания претерпевают значительное изменение (рис. 3б). В частности, полностью пропадает пик $\mathrm{S}_{11}$ и значительно снижается интенсивность пика $\mathrm{S}_{22}$. Причиной данного изменения спектров служит сдвиг уров-
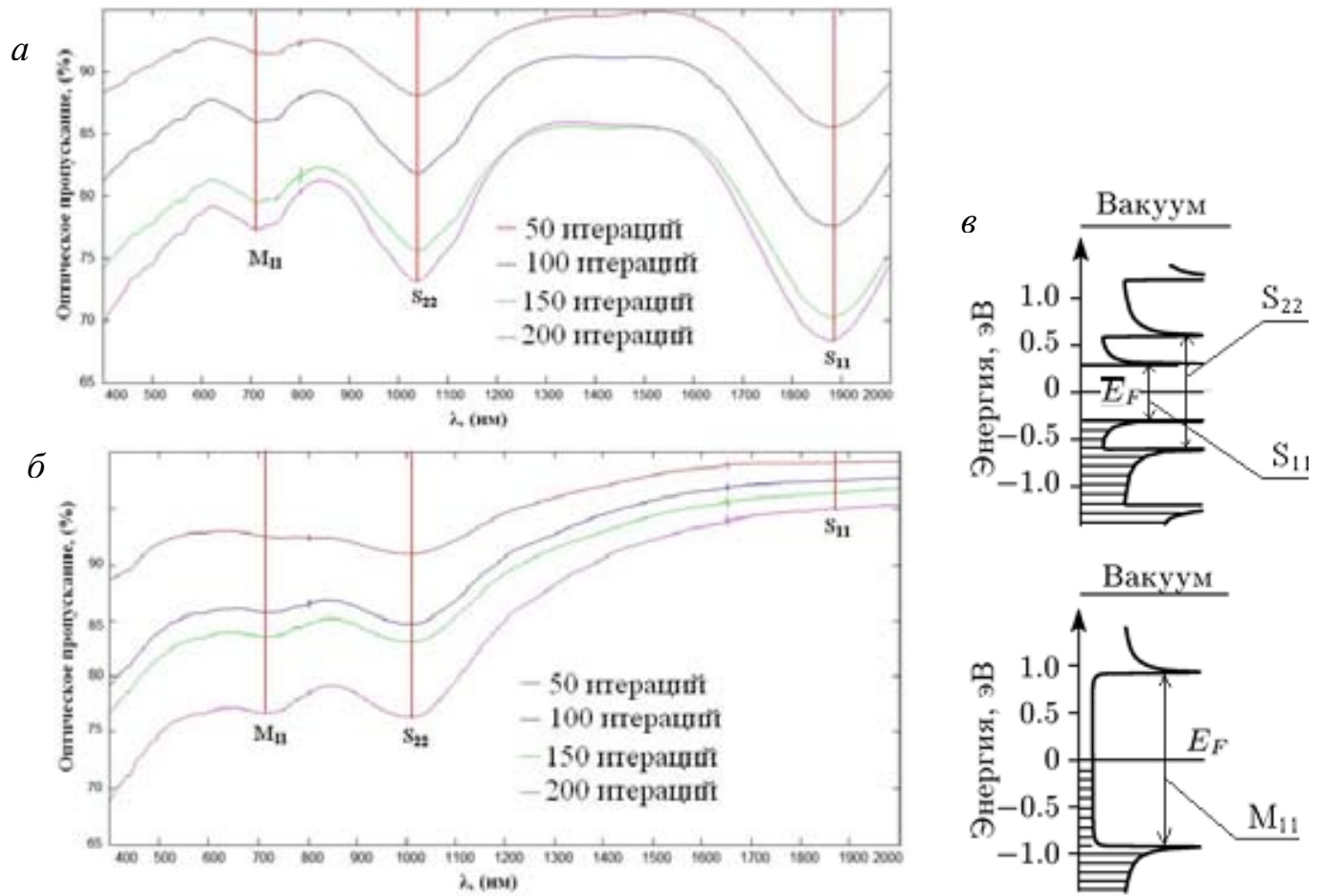

Рис. 3: $a$ - спектральные зависимости оптического пропускания исходных пленок ОУНТ; 6 - спектральные зависимости оптического пропускания пленок ОУНТ, экспонированных парами азотной кислоты; в - схематический вид функции плотности состояний для полупроводниковых и металлических ОУНT[14] 

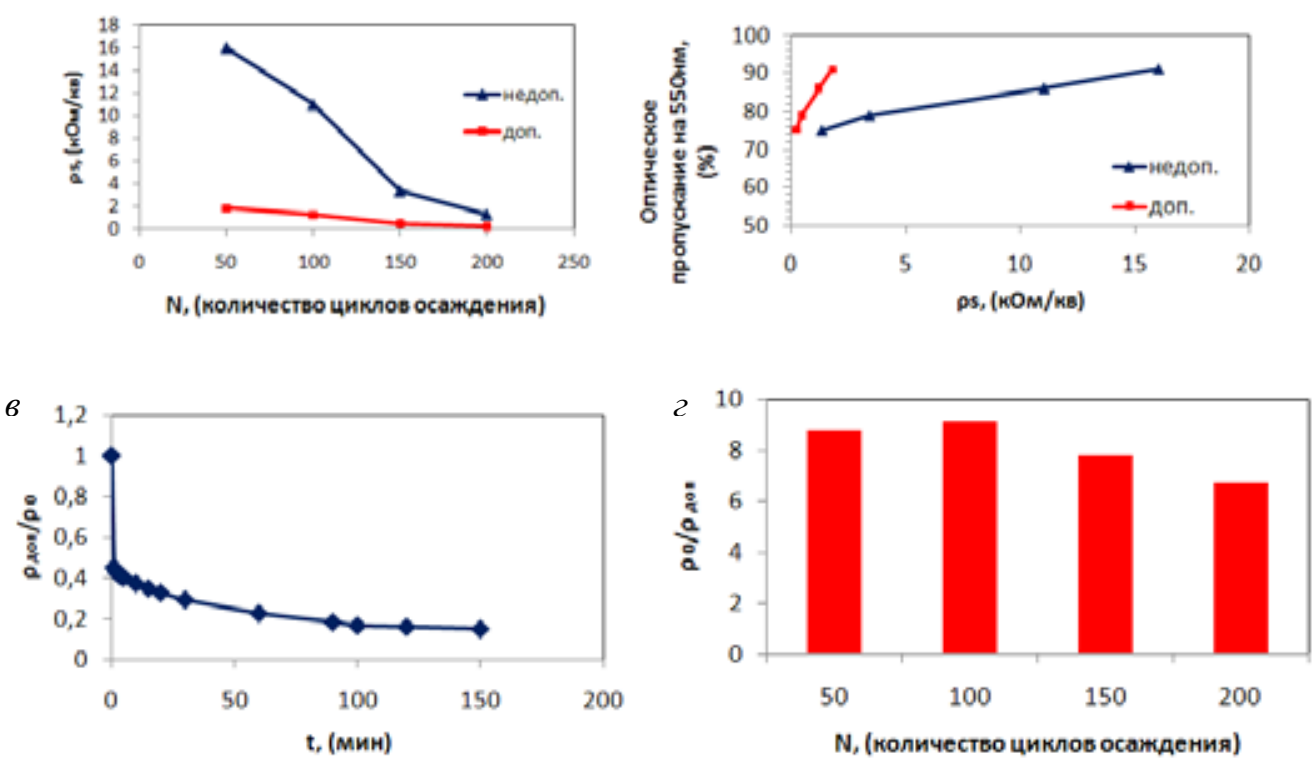

Рис. 4: $a$ - зависимость удельного поверхностного сопротивления пленок ОУНТ от количества итераций осаждения; $\sigma$ - зависимость оптического пропускания пленок ОУНТ от величины удельного поверхностного сопротивления; в - временная зависимость уменьшения поверхностного сопротивления для пленки толщиной 100 итераций; г - абсолютное уменьшение поверхностного сопротивления для пленок ОУНТ всех толщин

ня Ферми в валентную зону. Очевидно, что при этом уровень Ферми оказывается ниже первой сингулярности ван Хова для полупроводниковых нанотрубок. Как следствие, происходит опустошение энергетических уровней и электронные переходы между сингулярностями ван Хова становятся невозможными.

Неполное гашение пиков $\mathrm{S}_{22}$ и $\mathrm{M}_{11}$, по-видимому, связано с недостаточным временем обработки парами азотной кислоты.

На рис. $4 a$ представлены зависимости удельного поверхностного сопротивления пленок ОУНТ от количества итераций осаждения для случая недопированных и допированных пленок ОУНТ.

В целом операция допирования азотной кислотой позволяет увеличить проводимость пленок в 6-9 раз (рис. 42). В частности, на образце толщиной 200 итераций получено значение удельного поверхностного сопротивления 210 Ом/кв при оптическом пропускании 77 \% . Заслуживает внимания тот факт, что при операции химического допирования за счет подавления пиков поглощения в инфракрасной области происходит значительное просветление пленок. Так, удалось просветлить образец толщиной 200 итераций с 67 до 91 \% на длине волны 1873 нм, в то время как прозрачность наиболее востребованного коммерческого прозрачного покрытия (ITO) после длины волны 1200 нм начинает монотонно падать.

\section{Заключение}

В работе предложена методика получения пленок однослойных углеродных нанотрубок посредством ультразвукового распыления нанотрубного коллоидного раствора. Методика яв- 
ляется модификацией традиционного spray-метода. Уменьшение на порядок размера капель распыляемого аэрозоля улучшает однородность пленки ОУНТ и способствует получению более качественного покрытия по сравнению с покрытиями, получаемыми традиционным sprayметодом. При допировании пленок ОУНТ парами азотной кислоты их поверхностное сопротивление уменьшается в 6-9 раз. При этом за счет подавления электронных переходов между сингулярностями ван Хова происходит значительное просветление пленок ОУНТ, что уже сейчас позволяет рассматривать пленки ОУНТ как альтернативу ITO в приложениях, использующих инфракрасный диапазон.

\section{Список литературы}

[1] Hecht D.S., Hu, L.B., Irvin, G.// Adv.Mater. 2011. № 23. P. 1482.

[2] Tung T.S., Ho K.C. // Sol. Energ. Mat. Sol. 2006. № 90. P. 521.

[3] Liu H.Y., Avrutin V., Izyumskaya N. etc. //Superlattices Microstruct. 2010. № 48(5). P. 458.

[4] Wang X., Zhi L.J., Mullen K. // Nano Lett. 2008. № 8. P. 323.

[5] Minami T. // Semicond. Sci. Technol. 2005. № 20. P. 35.

[6] Iijima S. // Nature. 1991. № 354. P. 56.

[7] Ни L., Hecht D.S., Gruner, G.// Nano Lett. 2004. № 4. P. 2513.

[8] Feng C., Liu K., Wu J.S. etc. // Adv. Funct. Mater. 2010. № 20. P. 885.

[9] Pasquier A.D., Unalan H.E., Kanwal A. etc. // Appl. Phys. Lett. 2005. № 87. P. 203511.

[10] Jeong M., Lee K., Choi E. etc. // Nanotechnology. 2012. № 23. P. 505203

[11] Pu J., Wan S., Lu Z. etc. // J. Mater. Chem. A. 2013. № 1. P.1254.

[12] Scardaci V., Coull R., Coleman J.N.// Appl. Phys. Lett. 2010. № 97. P. 023114.

[13] Fischer T., Wetzold N., Elsner H. etc. // Nanomater. nanotechnol. 2011. № 1. P. 18.

[14] Shin D.W., Lee J.H., Kim Y.H. etc. // Nanotechnology. 2009. № 20. P. 475703.

[15] Jackson R., Domercq B., Jain R. etc. // Adv. Funct. Mater. 2008. № 18. P. 2548.

[16] Харламова М.В., Ниу Дж. // ЖЭТФ. 2012. Т. 142. Вып. 3(9). С. 547.

[17] Pekker A., Borondics F., Kamaras K. etc. // Phys. stat. sol. (b). 2006. № 13. P. 3485.

[18] Krupke R., Hennrich F., Lohneysen H., Kappes M.M. // Science. 2003. № 301. P. 344. 